\title{
Competencias del especialista en ortopedia y traumatología
}

\author{
Competencies of the specialist in orthopedics and traumatology
}

Gustavo Francisco Arenas Serna*

*Expresidente de la Federación Mexicana de Ortopedia y Traumatología, A.C. México.

No tengo dudas respecto a que nuestra especialidad médica es la más extensa de todas, atiende las afecciones del aparato locomotor de todas las etiologías, desde las de origen traumático, hasta las de tipo metabólico, pasando por degenerativas, inflamatorias, neoplásicas, congénitas y abarcando los padecimientos en todos los grupos etarios, desde el nacimiento hasta la ancianidad, tanto las patologías localizadas como las sistémicas. Cada segmento del sistema musculoesquelético puede presentar alguna de las múltiples alteraciones que existen en el ser humano y en cada región anatómica pueden existir cientos de formas de tratamiento físico, farmacológico o quirúrgico. Por lo anterior, la especialidad de Traumatología y Ortopedia resulta, además de fascinante, compleja. A cada minuto aparecen publicaciones científicas en el mundo que aportan conocimientos sobre datos anatómicos no descritos con anterioridad, sobre la evolución natural de las enfermedades que lo alteran, sobre nuevas modalidades terapéuticas, la etiología, epidemiología, patogenia y su pronóstico, se proponen técnicas quirúrgicas, se descartan por obsolescencia otras, se premian bajo el concepto de «estándar de oro» a aquéllas que a pesar de nuevas aportaciones no logran superar los resultados de esas anteriores, y toda esta producción científica debemos multiplicarla por cada segmento, articulación y región del cuerpo humano para darnos la idea de lo que un especialista tendría que estudiar y practicar para estar al día en todo lo relativo a la especialidad.

En los cursos de especialización en esta materia que se llevan a cabo en diferentes hospitales públicos y privados del sector salud, bajo el auspicio de las distintas universidades a través de sus divisiones de estudios de postgrado, se preparan a los médicos cirujanos en lo básico para otorgarles el diploma que los distingue como especialistas en Ortopedia y Traumatología, por supues-

Correspondencia:

Gustavo Francisco Arenas Serna

E-mail: drgarenas@yahoo.com.mx to que la formación que adquieren no es la misma si la cursaron en un hospital general, en uno de alta especialidad de tercer nivel o en uno exclusivo para la atención de pacientes afectados del aparato locomotor. La carga académica, la frecuencia de la práctica quirúrgica, variedad de patologías, diferentes escuelas donde quienes son sus maestros se formaron, número de residentes en relación a la capacidad y recursos hospitalarios son factores que hacen que este proceso resulte con características heterogéneas del producto formado.

El consejo mexicano de la especialidad pretende establecer un filtro para que sólo aquéllos que lograron obtener durante su proceso de formación un bagaje de conocimientos, destrezas y actitudes considerados como mínimos indispensables, se les certifique como «aptos» para ejercer la especialidad en nuestro país y dar oportunidad al resto para que sigan aprendiendo hasta lograr la certificación que la ley actual reconoce como requisito para ostentarse como especialista.

Una vez cumplido con lo anterior, el nuevo especialista busca dónde ubicarse para trabajar en su área de competencia que teóricamente sería la atención de todo tipo de pacientes afectados del sistema musculoesquelético, algunos obtienen empleo en hospitales del sector salud, otros se instalan en un consultorio particular y se afilian a algún hospital privado donde podrán tratar a los pacientes que lo requieran y otros logran la combinación de ambos, lo que les permite acumular experiencia propia en el ejercicio de la especialidad y obtener recursos económicos para financiar los gastos personales y familiares, que en esta etapa de la vida comúnmente corresponden a un matrimonio joven intentando cimentar las bases para su hogar.

Citar como: Arenas SGF. Competencias del especialista en ortopedia y traumatología. Orthotips. 2021; 17 (4): 188-189. https://dx.doi. org/10.35366/102214 
El inicio del trabajo como especialista normalmente abarca todo lo considerado como competencia del «ortopedista general», pero sus funciones son diferentes si se desempeña en un hospital de alta especialidad o en aquéllos de atención exclusiva del aparato locomotor, en los que se realiza como médico de primer contacto, por el contrario, si se integra a un servicio de ortopedia de un hospital general, él mismo será el responsable de la totalidad de los problemas ortopédicos. Algunos colegas compañeros en el hospital habrán tenido la oportunidad de realizar un curso de subespecialidad y, aunque no estén contratados como tales, la organización interna del servicio los utiliza para atender al tipo específico de pacientes que corresponda, si el hospital no cuenta con lo necesario para atenderlo por falta del recurso humano capacitado o de soporte tecnológico, normalmente puede referirlo a otra unidad en la que sí se disponga de este apoyo; en la situación económica que prevalece actualmente en el sector salud, encuentra muchas trabas administrativas, lo que resulta que ese ortopedista se vea obligado a resolver el problema con los recursos limitados con los que se cuente.

Nos ha tocado vivir el cambio evolutivo entre el ortopedista general, responsable de atender a los pacientes de cualquier edad, portadores de los diversos tipos de patologías de cualquier región del sistema musculoesquelético, y el desarrollo de las subespecialidades.

En los hospitales de alta especialidad, los servicios ortopédicos se encuentran divididos por áreas y en cada una de ellas laboran los ortopedistas que han adquirido la experiencia necesaria con los años de trabajo dedicados a esa tarea específica o han realizado el curso de subespecialidad correspondiente, pero ¿qué sucede en los hospitales generales? En las ciudades pequeñas, y aunque con menos frecuencia también en las mayores, el ortopedista general o el subespecializado atiende por igual a cualquier tipo de paciente que acuda al servicio y ahí surge una pregunta ies esto correcto, sabiendo que se dispone del especialista específico para el tipo de problema por el que acude el paciente a buscar nuestra atención?, se supone que sí, porque es un ortopedista calificado y certificado, pero ¿resulta ético que se le omita la información de que en el mismo hospital existe un especialista que puede estar más capacitado que el primero para resolver su problema? Este es un asunto administrativo porque él no está contratado como subespecialista y todos los integrantes del servicio tienen la misma carga laboral. Y si nos enfocamos en el medio privado, surge otro cuestionamiento aún más espinoso ¿es justo que el «general» deje de ganar la remuneración que le correspondería si él sólo realizara el tratamiento completo y por razones éticas se lo envía al colega especializado? Sin duda son preguntas que, con la proliferación de tantas subespecialidades y médicos que han logrado obtenerlas, los cuales en sus consultorios no tienen el volumen deseado de pacientes exclusivos de la competencia otorgada y que por tanto tienen la necesidad de abarcar los que corresponderían a otras áreas de la especialidad, no tienen una clara respuesta.

Por otra parte, los que ya se especializaron y se dedican por completo al ejercicio de la misma caen en el mismo conflicto del general, que no les alcanza el tiempo para mantenerse actualizados en el amplísimo campo de todas las disciplinas, ellos asisten a los congresos y estudian las publicaciones fundamentalmente relacionadas con su especialidad, pero la necesidad económica les hace abarcar más allá de lo que están debidamente preparados para atender.

Si analizamos ahora el aspecto de la confianza del paciente que acude con el «ortopedista general», lo hace porque su prestigio le genera confianza, pero si él, consciente de que su colega «especializado» puede ofrecerle mejores resultados, por la misma ética decide enviárselo, se genera tal incertidumbre que posiblemente el caso se pierda entre ambos.

¿Cómo mantener la confianza del paciente hacia nosotros?, ¿cómo debemos actuar desde el punto de vista ético?, ¿cómo podemos evitar la pérdida de ingresos económicos?

La propuesta se basa en que tanto en el medio público como en el privado, los ortopedistas debemos conformar grupos de atención multidisciplinarios para llamar, si fuera necesario, al más capaz para colaborar en el tratamiento de su paciente para que sin engaños o protagonismos se le ofrezca lo que más le convenga a sabiendas que trabajarán como equipo, sin que el primero se desprenda de la responsabilidad como su médico de confianza, quien se hará cargo del seguimiento hasta su recuperación total. En esta labor de equipo se debe evitar el costo exagerado para el paciente, estableciendo acuerdos sobre honorarios de uno y otro en forma mesurada y no simplemente duplicarlos. De esta forma, se conserva la confianza que depositó la persona, se cumple con el aspecto ético al llamar a colaborar al más capaz y se obtiene una remuneración razonable.

El papel del «Ortopedista General» es tan importante como el del «Médico de Cabecera» en el campo de la medicina general y la multiespecializada. 